\title{
Penyuluhan Teknik Pembuatan Lubang Biopori dalam Pencegahan Banjir di Desa Pemalongan Kecamatan Pelaihari Kabupaten Tanah Laut
}

\author{
Extension of Bioporical Hole Techniques in Flood Prevention in Pemalongan Village Sub \\ District of Pelaihari, Tanah Laut District
}

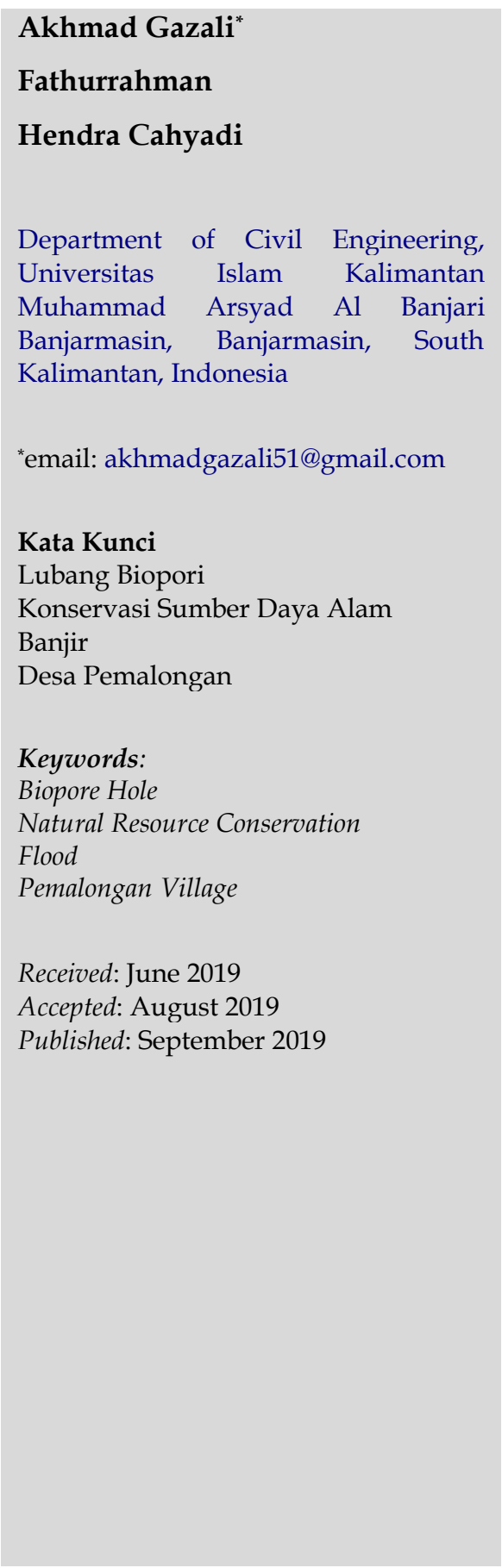

\begin{abstract}
Abstrak
Pemanfaatan lahan yang tidak sesuai dengan kaidah-kaidah konservasi dan melampaui kemampuan daya dukungnya, akan menyebabkan terjadinya lahan kritis. Disamping itu perilaku masyarakat yang belum mendukung pelestarian tanah dan lingkungan menyebabkan terjadinya bencana alam banjir pada musim penghujan. Perlu upaya untuk meningkatkan pengelolaan sumber daya air, yaitu untuk menjaga agar kuantitas air tanah tetap terjaga sehingga menjamin ketersediaan air bagi masyarakat. Pengembangan sumur resapan dan pembuatan lubang biopori ini dimaksudkan sebagai media menahan dan menyimpan air hujan. Lubang biopori adalah teknologi lingkungan yang murah dan baik. Modal utama adalah keinginan dan kesadaran manusia untuk menyelamatkan lingkungan mereka dari ketersediaan air dan polusi air. Penyuluhan teknik pembuatan lubang biopori dilakukan dengan metode ceramah disertai tanya jawab, dan demonstrasi. Metode ceramah diperlukan untuk menjelaskan konsep upaya pengelolaan dan kelestarian keberadaan sumber air serta lubang biopori secara umum, sedangkan tanya jawab untuk memberi kesempatan para peserta lebih memahami konsep sehingga bagi yang belum paham dapat menanyakan. Metode demonstrasi diperlukan untuk memperjelas proses teknik dan tahapan cara pembuatan biopori.
\end{abstract}

\begin{abstract}
Land use that is not in accordance with conservation rules and exceeds the capacity of its carrying capacity, will cause critical land. The behavior of the people who have not supported the preservation of land and the environment have caused floods in the rainy season. Efforts are needed to improve the management of water resources, namely to keep the quantity of groundwater maintained so as to ensure the availability of water for the community. The development of infiltration wells and making biopore holes is intended as a medium to hold and store rainwater. Biopori holes are cheap and good environmental technology. The main capital is human desire and awareness to save their environment from water availability and water pollution. Extension of biopore hole making techniques is done by the lecture method along with questions and answers and demonstrations. The lecture method is needed to explain the concept of management efforts and the sustainability of the existence of water sources and biopore holes in general, while the question and answer to give the opportunity for participants to better understand the concept so that those who do not understand can ask. Demonstration methods are needed to clarify the process of the technique and the stages of making biopore.
\end{abstract}




\section{PENDAHULUAN}

Membuat lubang biopori adalah solusi teknologi ramah lingkungan untuk mengatasi ketersediaan air tanah dengan memanfaatkan sampah organik melalui lubang kecil di tanah. Air dan sampah adalah hal-hal yang tidak dapat dipisahkan dari kehidupan makhluk hidup, termasuk manusia. Setiap manusia menghasilkan sampah dari aktivitasnya sehari-hari. Terkadang sampah menjadi sumber masalah pencemaran lingkungan, padahal sampah memiliki potensi besar dalam menyelamatkan lingkungan, jika diolah dengan bijak dan bijak. Adapun air, sangat penting untuk makhluk hidup. Tanpa air, makhluk hidup akan mati. Oleh karena itu, perlu untuk mengolah air dan sampah untuk mempertahankan kehidupan (Yohana et al., 2017). Pembuatan biopori dapat dilakukan dimana saja, dengan ketersediaan tanah yang tidak terlalu luas. Teknologi yang dikembangkan oleh Brata (2006) sangat cocok diterapkan di wilayah perkotaan yang tanahnya penuh bangunan sehingga penyerapan air menjadi minim. Dengan memanfaatkan lubang kecil dan sampah organik maka wilayah perkotaan yang terlihat kering dan gersang akan berubah menjadi wilayah yang ramah lingkungan.

Pemanfaatan sumber daya alam yang berupa tanah dan air sebagai salah satu modal dasar pembangunan nasional, harus dilaksanakan sebaik-baiknya berdasarkan azas kelestarian, keserasian dan azas pemanfaatan yang optimal, yang dapat memberikan manfaat ekonomi, ekologi dan sosial secara seimbang (Nursalam, 2010). Penggunaan pemanfaatan tanah dan lahan yang tidak sesuai dengan kaidah-kaidah konservasi dan melampaui kemampuan daya dukungnya, akan menyebabkan terjadinya lahan kritis (Kubangun et al., 2014). Disamping itu perilaku masyarakat yang belum mendukung pelestarian tanah dan lingkungan menyebabkan terjadinya bencana alam banjir pada musim penghujan (Hong et al., 2014; Taryono, 1992).

Dalam rangka pemanfaatan sumber daya alam baik berupa tanah dan air perlu direncanakan dan dikelola secara tepat melalui suatu sistem pengelolaan Lubang Resapan Biopori (LRB). Untuk menghindari hal tersebut di atas perlu dilakukan upaya pelestarian lahan kritis, dan pengembangan fungsi lubang biopori terus ditingkatkan dan disempurnakan. Lubang Biopori pada lahan kritis dimaksudkan untuk memulihkan kesuburan tanah, melindungi tata air, dan kelestarian daya dukung lingkungan (Sembel \& Rondonuwu, 2016). Salah satu upaya pokok dalam pengelolaan LRB adalah berupa pengaturan keseimbangan pada lingkungan yang kurang daerah peresapan. Brata (2009) menjelaskan biopori adalah lubang sedalam $80-100 \mathrm{~cm}$ dengan diameter 10-30 cm, dimaksudkan sebagi lubang resapan untuk menampung air hujan dan meresapkannya kembali ke tanah. Biopori memperbesar daya tampung tanah terhadap air hujan, mengurangi genangan air, yang selanjutnya mengurangi limpahan air hujan turun ke sungai (Santosa et al., 2018).

Dari aspek perencanaan ditempuh melalui penyempurnaan pembuatan biopori di lingkungan sekitar masyarakat. Di akspek inilah diharapkan akan dapat menjadi acuan pelaksanaan pembuatan biopori oleh semua kalangan masyarakat (Ulfah et al., 2016). Biopori secara umum, dapat mengurangi resiko bahaya banjir di daerah yang kurang lahan peresapan air. Tidak hanya sebagai pencegah banjir, penerapan biopori yang secara rutin akan menghasilkan pupuk kompos yang sangat bermanfaat (Widyastuty et al., 2019). Solusi pemecahan masalah yang diajukan secara operasional untuk menjawab permasalahan yang ada tersebut yaitu dengan menyelenggarakan penyuluhan pentingnya pembuatan lubang biopori dan teknik pembuatan lubang biopori di Desa Pemalongan, Kecamatan 
Pelaihari, Kabupaten Tanah Laut. Tujuan yang ingin dicapai dari kegiatan pengabdian ini adalah meningkatkan kesadaran manusia akan pentingnya ketersediaan air dan pengolahan sampah organik serta mengetahui tentang cara pembuatan lubang resapan biopori yang efektif dan efisien untuk masyarakat di Desa Pemalongan, Kecamatan Pelaihari, Kabupaten Tanah Laut

\section{METODOLOGI}

\section{Cara Pembuatan Lubang Resapan Biopori}

Setelah mengetahui pemahaman tentang biopori, manfaat yang dapat diperoleh dari penerapannya, dan lokasi perencanaan yang tepat untuk biopori. Maka langkah terakhir yaitu mengetahui bagaimana cara pembuatan biopori yang disarankan oleh para ahli. Adapun cara pembuatannya adalah sebagai berikut:

1. Membuat lubang silindris di tanah dengan diameter 10-30 cm dan kedalaman 30-100 cm serta jarak antar lubang $50-100 \mathrm{~cm}$.

2. Mulut lubang dikuatkan dengan semen setebal $2 \mathrm{~cm}$ dan lebar 2-3 centimeter serta diberikan pengaman agar tidak ada anak kecil atau orang yang terperosok.

3. Lubang diisi dengan sampah organik seperti daun, sampah dapur, ranting pohon, sampah makanan dapur non kimia, dan lain-lain. Sampah dalam lubang akan menyusut sehingga perlu diisi kembali dan di akhir musim kemarau dapat dikuras sebagai pupuk kompos alami.

4. Jumlah lubang biopori dihitung berdasarkan besar kecil hujan, laju resapan air dan wilayah yang tidak meresap air dengan rumus = intensitas hujan (mm/jam) x luas bidang kedap air (meter persegí)/laju resapan air perlubang (liter /jam).

Secara ringkas deskripsi lubang resapan biopori dapat dilihat pada Gambar 1 berikut.

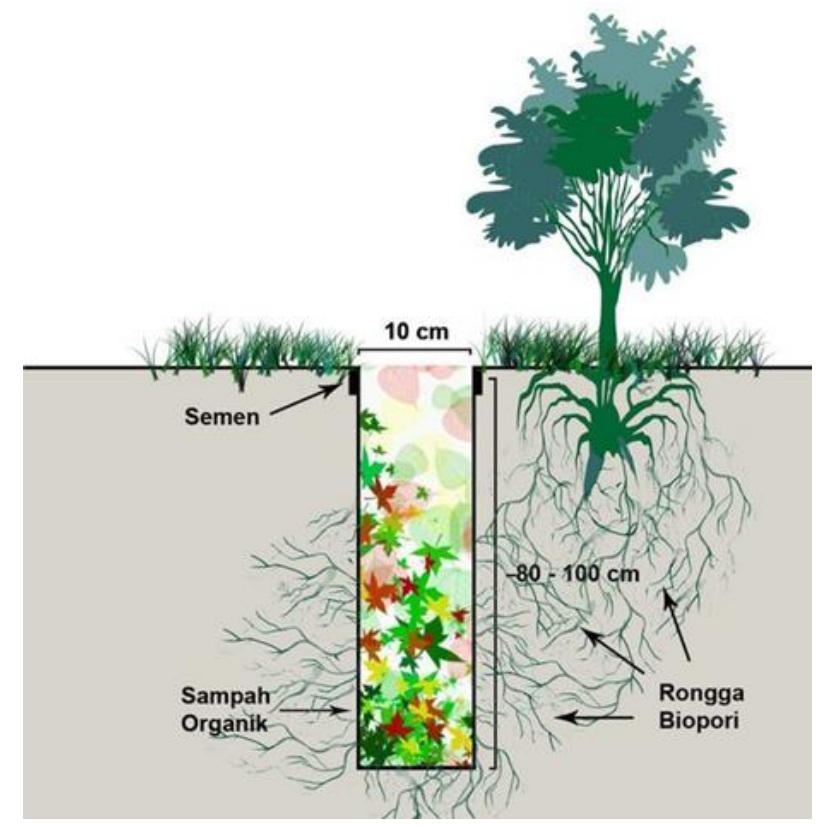

Gambar 1. Lubang Resapan Biopori (Sumber: https://madiunberkebun.files.wordpress.com/2011/11 /lubang-biopori.jpg)

\section{Metode Pelaksanaan}

Kegiatan ini direncanakan diikuti oleh warga Desa Pemalongan, Kecamatan Pelaihari, Kabupaten Tanah Laut dengan melibatkan Ibu-lbu anggota PKK di beberapa RW. Hal ini disebabkan karena kaum Ibu adalah orang pengguna air dan penghasil sampah terbesar sebagai dampak dari aktivitas memasak di dapur. Kegiatan penyuluhan ini dengan melibatkan 30 orang. Kegiatan dilakukan pada beberapa RW di Desa Pemalongan, Kecamatan Pelaihari, Kabupaten Tanah Laut yang potensial terhadap genangan air dan sempitnya tanah sebagai penyerap air (Sanitya \& Burhanudin, 2013). Tahapan kegiatan yang akan dilakukan adalah sebagai berikut:

1. Tahap persiapan

Tahap persiapan dalam kegiatan pengabdian ini adalah penyusunan pre-planning. Persiapan media berupa power point dengan materi penyuluhan mengenai teknik pembuatan lubang biopori. Langkah pertama adalah membuat kontrak, waktu dan tempat penyuluhan dengan mitra setempat. 


\section{Tahap pelaksanaan}

Kegiatan penyuluhan ini dilakukan dengan cara mengumpulkan warga dengan koordinasi mitra. Materi akan diberikan kepada para peserta berupa buku dan gambar-gambar. Diakhir pemberian ceramah peserta dipersilahkan diberi kesempatan untuk melakukan tanya jawab dengan narasumber. Diharapkan dari sini maka para peserta akan mengerti dan dapat memberikan masukan kepada orang tua dan keluarga mereka.

Secara ringkas metodologi kegiatan dapat dilihat pada Gambar 2 berikut ini:

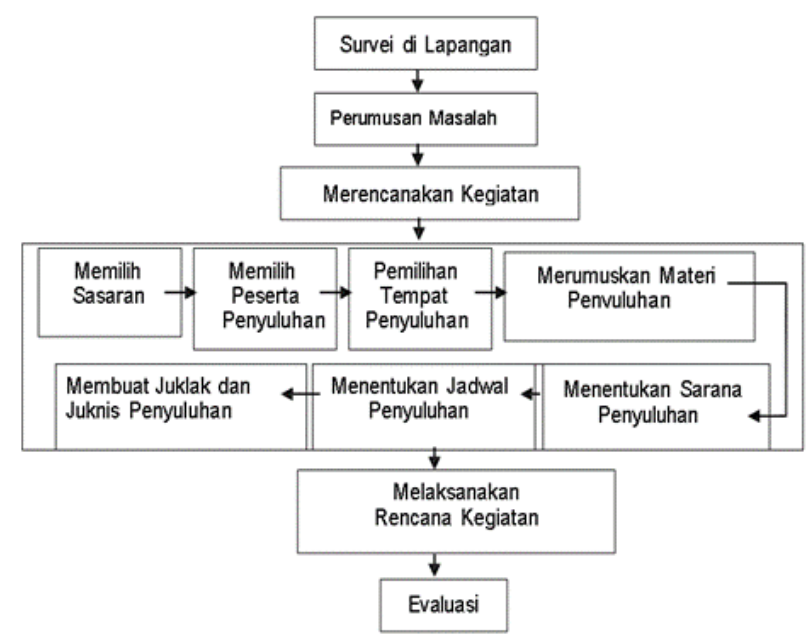

Gambar 2. Diagram Alir Kegiatan Pengabdian Kepada Masyarakat

\section{HASIL DAN PEMBAHASAN}

Pembuatan lubang resapan biopori, membutuhkan kemampuan dan kesadaran yang tinggi terhadap upaya penyelamatan lingkungan dari kurangnya ketersedaiaan air pada musim kemarau dan melimpahnya air hujan disaat musim penghujan (Utama et al., 2018). Pembuatan lubang resapan biopori lebih tepat dilakukan oleh kaum ibu rumah tangga, karena lubang ini diisi oleh sampah organik sisa rumah tangga yang kemudian dibiarkan membusuk dan menjadi tempat berkembangnya mikrobia tanah untuk membuat pori-pori dalam tanah sebagai tempat untuk menjebak air hujan, sehingga proses penyerapan air hujan dalam tanah lebih maksimal.

Pembuatan lubang resapan biopori sangat penting dilaksanakan terutama di daerah yang padat penduduk, dan lokasi tanah penyerapan air sangat minim, sehingga lokasi tersebut sering bermasalah dengan air hujan, seperti genangan air, banjir bahkan munculnya berbagai penyakit yang diakibatkannya, seperti demam berdarah, malaria dan sebagainya (Harris, 2015). Kelebihan dari lubang resapan biopori adalah minimnya lahan yang digunakan untuk menanam sampah organik, karena hanya membutuhkan tanah seluas 10-30 $\mathrm{cm}^{2}$ dengan kedalaman 50-100 cm. Lubang yang dibuat dapat menampung sampah organik dengan volume kurang lebih $30 \mathrm{~L}$ tanpa menimbulkan bau busuk karena sempitnya luas permukaan tempat pembusukan sampah bau dan lubang tersebut bisa ditutup untuk mengurangi penyebaran bau (Yohana et al., 2017).

Beberapa kendala dalam pembuatan lubang resapan biopori bagi warga di perkotaan, antara lain mahalnya alat pembuat lubang di dalam tanah (bor tanah) seharga dua ratus ribu rupiah jika harus di miliki oleh setiap warga (rumah tangga). Namun kendala seperti ini bisa disiasati dengan pembelian secara berkelompok oleh beberapa rumah tangga yang penggunaannya dapat dilakukan secara bersama-sama (bergiliran). Beberapa kelompok warga di perkotaan sudah mulai menerapkan sistem seperti ini. misalnya dalam satu kelompok dasa wisma (Nurdiani et al., 2015). Pemerintah sebagai pihak yang berfungsi untuk mengatur dan mengendalikan kesejahteraan warga, seharusnya bertanggung jawab untuk menyediakan alat bor tanah untuk mengatasi minimnya ketersediaan air di musim kemarau dan banjir di musim hujan. Kepedulian ini antara lain bisa diwujudkan dalam bentuk pemberian alat bor tanah bagi lokasi-lokasi yang rawan genangan air, khususnya 
didaerah perkotaan yang padat penduduk dengan luas tanah penyerap air sangat minim.

Berdasarkan kebutuhan lapangan dalam rangka mendukung program pemerintah dalam mengatasi kesediaan air dan penyelamatan lingkungan ini, maka tim pengabdian pada masyarakat Universitas Islam Kalimantan Muhammad Arsyad Al Banjari Banjarmasin melakukan kegiatan penyuluhan dan praktek pembuatan lubang biopori di wilayah Kabupaten Tanah Laut, terutama Kecamatan Pelaihari. Hal ini dilakukan sebagai upaya untuk menyadarkan masyarakat terhadap pentingnya biopori dalam mengatasi kelebihan sampah dan kekurangan ketersediaan air. Dokumentasi kegiatan pengabdian dapat dilihat pada Gambar 3 berikut ini.

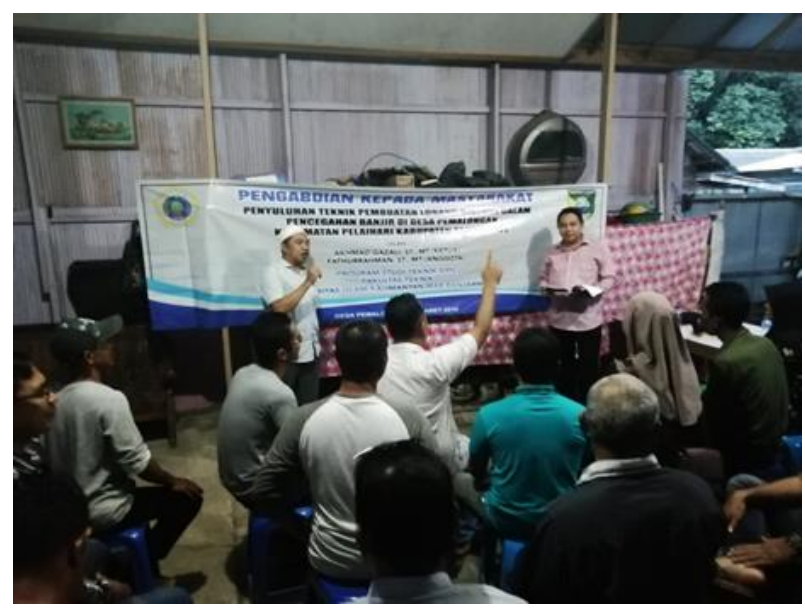

Gambar 3. Kegiatan Penyuluhan Bersama Warga Desa Pemalongan

\section{KESIMPULAN}

Pembuatan lubang resapan biopori masih sangat perlu untuk digalakkan di wilayah Kabupaten Tanah Laut yang mempunyai luasan genangan air sebesar 7,6 Ha. Sementara saat ini pembuatan lubang biopori masih sangat minim di wilayah Pelaihari, sehingga perlu adanya dukungan dari Pemerintah dan seluruh elemen masyarakat, termasuk Perguruan Tinggi yang mempunyai tugas untuk pengabdian kepada masyarakat. Diharapkan dengan adanya pelaksanaan program pembuatan lubang biopori ini dapat mengurangi luasan genangan air di wilayah Kabupaten Tanah Laut

\section{UCAPAN TERIMA KASIH}

Program PPDM ini terlaksana atas bantuan dan dukungan pendanaan dari Universitas Islam Kalimantan Muhammad Arsyad Al Banjari Banjarmasin, dukungan administrasi dari LPPM Universitas Islam Kalimantan Muhammad Arsyad Al Banjari Banjarmasin, kerjasama dari Kepala Desa beserta segenap jajaran dan warga Desa Pemalongan Kecamatan Pelaihari Kabupaten Tanah Laut, serta dukungan dari civitas akademika Fakultas Teknik Universitas Islam Kalimantan Muhammad Arsyad Al Banjari Banjarmasin.

\section{REFERENSI}

Brata, K.R. 2006. Teknologi Biopori. Bogor: IPB Press.

Brata, K.R. 2009. Lubang Resapan Biopori untuk Mitigasi Banjir, Kekeringan dan Perbaikan. In Prosiding Seminar Lubang Biopori (LBR) dapat Mengurangi Bahaya banjir di Gedung BPPT 2009. Jakarta: Badan Pengkajian dan Penerapan Teknologi.

Harris, S. 2015. Pemanfaatan Bak Resapan dan Biopori Sistem Guna Mengatasi Masalah Genangan Air. Faktor Exacta. 8(3):186-194. http://dx.doi.org/10.30998/faktorexacta.v8i3 .320

Hong, W., Li, F., Zhang F., Tong, L., Huang, Q. 2014. Toward a Sustainable Utilization of Land Resources in China: Problems, Policies, and Practices. Ambio. 43(6):825-835. https://dx.doi.org/10.1007/s13280-013-04649

Kubangun, S.H., Haridjaja, O., Gandasasmita, K. 2014. Model Spasial Bahaya Lahan Kritis di Kabupaten Bogor, Cianjur dan Sukabumi. Majalah Ilmiah Globe. 16(2):149-156. 
Nurdiani, N., Ardiani, Y.M., Suharjanto, G. 2015. Pemberdayaan Masyarakat dalam Peningkatan Kualitas Lingkungan Permukiman Melalui Pelatihan dan Pembuatan Lubang Resapan Biopori. In Prosiding Seminar Nasional Keberlanjutan Ruang Huni Masa Depan EKO-ARSITEKTUR. Jakarta: Universitas Trisakti.

Nursalam. 2010. Kebijakan Pelestarian Sumber Daya Hutan dalam Rangka Pembangunan Berkelanjutan. Jurnal Geografi Gea. 10(1):1-14. http://dx.doi.org/10.17509/gea.v10i1.1660

Sanitya, R.S., Burhanudin, H. 2013. Penentuan Lokasi dan Jumlah Lubang Resapan Biopori di Kawasan DAS Cikapundung Bagian Tengah. Jurnal Perencanaan Wilayah dan Kota. 13(1):1-14. https://doi.org/10.29313/jpwk.v13i1.1385

Santosa, S., Soekendarsi, E., Hassan, M.S., Fahruddin, Litaay, M., Priosambodo, D. 2018. Biopori dan Biogranul Kompos sebagai Upaya Peningkatan Peduli Lingkungan di SMAN 4 Kabupaten Soppeng. Abdimas: Jurnal Pengabdian Masyarakat Universitas Merdeka Malang. 3(Khusus):1-5.

Sembel, A.S., Rondonuwu, D.M. 2016. Kualitas Lingkungan melalui Pembuatan Lubang Resapan Biopori. Media Matrasain. 13(3):62-70.

Taryono. 1992. Environmentally Friendly Concept in Spatial Regulation. Forum Geografi. 6(11):82-92. https://doi.org/10.23917/forgeo.v6i2.398

Ulfah, M., Dewi, E.R.S., Rahayu, P., Dewi, L.R. 2016. Pengelolaan LRB sebagai Upaya Meningkatkan Daya Resap Air Pada Tanah. EDimas: Jurnal Pengabdian kepada Masyarakat. 7(1):27-37. http://dx.doi.org/10.26877/edimas.v7i1.1036

Utama, W.G., Purnami, W., Madu, F.J. 2018. Pembuatan Lubang Resapan Biopori (LRB Di Lingkungan SDI Konggang Kecamatan Langke RembongManggarai. JIPD (Jurnal Inovasi Pendidikan Dasar). 2(1):112-121.

Widyastuty, A.A.S.A., Adnan, A.H., Atrabina, N.A. 2019. Pengolahan Sampah Melalui Komposter dan Biopori di Desa Sedapurklagen Benjeng Gresik. Jurnal Abadimas Adi Buana. 3(1):21-32.

Yohana, C., Griandini, D., Muzambeq, S. 2017. Penerapan Pembuatan Teknik Lubang
Biopori Resapan Sebagai Upaya Pengendali Banjir. Jurnal Pemberdayaan Masyarakat Madani. 1(2):196-308. https://doi.org/10.21009/JPMM.001.2.10 